\title{
The Comparation of Anthropometric and Metabolic Indices in the Regulation and Prediction of Fatty Liver: a population-based cross- sectional study in China
}

\author{
Fangfei Xie \\ the Affilicated Suzhou Hospital of Nanjing Medical University \\ Yuyu Pei \\ the Affilicated Suzhou Hospital of Nanjing Medical University \\ Yun Wang \\ the Affilicated Suzhou Hospital of Nanjing Medical University \\ Jiongyan Li \\ the Affilicated Suzhou Hospital of Nanjing Medical University \\ Xuehua Xu \\ the Affilicated Suzhou Hospital of Nanjing Medical University \\ Hong Zhou \\ the Affilicated Suzhou Hospital of Nanjing Medical University \\ Kangyun Sun ( $\boldsymbol{\nabla} 714388761 @ q q . c o m$ )
}

\section{Research}

Keywords: Fatty liver, Anthropometric and metabolic indices, obesity

Posted Date: July 30th, 2020

DOI: https://doi.org/10.21203/rs.3.rs-45312/v1

License: (c) (1) This work is licensed under a Creative Commons Attribution 4.0 International License. Read Full License 


\section{Abstract}

Background: The association between anthropometric and metabolic indices and fatty liver $(\mathrm{FL})$ remain not fully elucidated. We aimed to determine the role of these anthropometric and metabolic indices on FL prediction and regulation via cross-sectional study, thus providing clues for further research in FL field.

Methods: A total of 658 participants aged over 18 years were included in this study. Anthropometric and metabolic indices (including WC, WHR, BMI, BFM, VFA, TG/HDL, AST/ALT, SBP, DBP and FBG) were measured. Difference analyses, logistic and predictive analyses were used to evaluate the association and discrimination ability between these indices and FL.

Results: Compared with non-FL, anthropometric and metabolic indices in FL and mild FL people showed a significant increase after adjustment. In the multivariate ranked logistic regression analysis, WC, TG/HDL, AST/ALT and FBG have a strong association with FL $(\beta=0.03,0.19,0.41,-1.89$ and 0.28 , $\mathrm{P}<0.05)$. And AST/ALT showed the lowest predicted power with an AUC of 0.22 among all indices. WC showed to be the best predictors with an AUC of 0.86 in participants.

Conclusions: This is a comprehensive profile for FL related indices. These can enhance our understanding of the mechanisms for hepatic on inflammation and fat and is also important for the prevention and treatment of FL.

\section{Background}

Epidemiological studies indicated that Fatty Liver (FL) had became a global problem of public health over the past few decades with the incidences around $30 \%$ and $25 \%$ in Western and Asia countries, which also caused huge medical burden in both developed and developing countries [1-5]. FL is also characterized by complex pathogenesis and difficulty in diagnosis[6, 7]. Thus, it is of great necessity to further explore the pathogenesis or the prediction for the diagnosis of FL. FL is commonly associated obesity, type $₫$ diabetes, dyslipidemia, and metabolic disorders[8-12]. The relationship

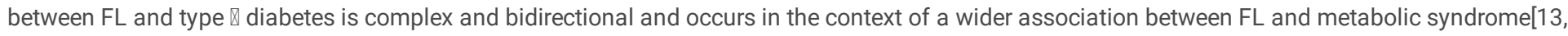
14]. In the last decades, an alarming increase in the prevalence of FL has been observed, along with increasing rates of obesity[15]. Some studies found regional distribution of lean and fat mass may influence the development of FL and suggested that abdominal fat are risk factors for fatty liver and more advanced fatty liver related fibrosis[7, 11]. In recent years, several anthropometric or metabolic indices had been reported to be associated with FL in both cross-sectional and cohort studies[16-23]. However, most existing studies mainly focused on common indices (such as waist, body mass index, triglyceride and blood glucose). The association of other indices (such as waist-hip ratio, visceral fat area and transamination) with FL, which might be even more important than common indices, remain unclear. Exploring correlation profile between these indices and FL would facilitate the understanding of the complex regulatory mechanisms and provide clues for further research. Herein, we explored the comprehensive relationship between multiple indices and FL and we hypothesized that anthropometric and metabolic indices have regulatory and predictive effects on FL with a very complex pattern.

\section{Materials And Methods}

Study population

The study subjects were recruited in physical examination Center of Suzhou in southeast of China, during January 2018 to December 2019.

Participants in this study were Chinese Han ethnicity ageing over 18 years. After excluding subjects for lacking data, a total of 658 subjects were finally included in the analysis. The study was approved by the ethical committee of the Affiliated Suzhou Hospital of Nanjing Medical University and all subjects agreed to participate into the present study.

Data collection

Health examination was performed in the morning by trained medical staff. Anthropometric indices, including Waist Circumference (WC), Waist-hip Ratio (WHR), Body Mass Index (BMI), Body Fat Mass (BFM) and Visceral Fat Area (VFA), were measured by the InBody770 analyzer which can estimate body composition with small individual error[24]. The participants were instructed to stand upright and to grasp the handles of the analyzer, thereby providing contact with a total of eight electrodes. Metabolic markers,including Triglyceride(TG), High Density Lipoprotein(HDL), Glutamic oxaloacetylase(AST), Alanine aminotransferase(ALT), and Fasting Blood Glucose (FBG), were measured biochemically within 3 hours after peripheral blood drawn. TG/HDL and AST/ALT was calculated as the ratio of TG to HDL and AST to ALT, respectively. Systolic blood pressure (SBP) and diastolic blood pressure (DBP) were measured by sphygmomanometer following standard procedure. Diagnoses of FL was based on the four abdominal ultrasonography standard (parenchymal brightness, hepatorenal echo contrast, deep beam attenuation, and bright vessel walls) by experienced radiologists with expertise in liver imaging[25, 26].

\section{Statistical analysis}

All participants were divided into FL, Mild-FL and non-FL groups. The baseline variables (gender, age, anthropometric and metabolic indices) were compared using the Chi-square test and Rank tests appropriately. All measurement data are expressed as mean \pm standard deviation. Univariate and multivariate ranked logistic regression analyses were conducted to evaluate the association between anthropometric, metabolic indices and FL. Odd 
Ratios (OR) were obtained from logistic regression analysis, and the results were presented as OR with 95\% Confidence Interval (CI). Area Under the Curve (AUC) of Receiver Operating Characteristic (ROC) was calculated to compare the predictive value between these indices for predicting FL. All statistical analyses were performed with the Statistical Package for the Sciences (SPSS, version 17.0). A value of $P<0.05$ in two-tailed test was considered significant.

\section{Results}

A total of 658 subjects were included in our study, including 98 (14.89\%) FL patients, 88 (13.37\%) Mild-FL patients, and 472 (71.73\%) controls. Among FL and Mild-FL patients, $87.75 \%$ and $85.22 \%$ individuals were males, which was significantly higher than those in females $(12.25 \%$ and $14.78 \%$, $P<$ 0.01). The mean age of three groups were $45.20 \pm 11.35,45.78 \pm 10.70$ and $43.42 \pm 11.50$, respectively. Table 1 compared the demographic characteristics, anthropometric and metabolic indices of individuals in three groups. Significant differences were observed among the groups. After adjustment for gender, the differences remained to be significant $(P<0.01)$. (Table 1)

Table 1

Baseline Characteristics, Anthropometric and Metabolic Indices of Recruited Subjects Stratified by Gender

\begin{tabular}{|c|c|c|c|c|c|c|c|c|c|c|c|c|}
\hline & \multicolumn{4}{|l|}{ All } & \multicolumn{4}{|l|}{ Male } & \multicolumn{4}{|l|}{ Female } \\
\hline & $\mathrm{FL}$ & Mild-FL & Non-FL & $\begin{array}{l}P \\
\text { value }\end{array}$ & $\mathrm{FL}$ & $\begin{array}{l}\text { Mild- } \\
\text { FL }\end{array}$ & Non-FL & $\begin{array}{l}\mathrm{P} \\
\text { value }\end{array}$ & FL & $\begin{array}{l}\text { Mild- } \\
\text { FL }\end{array}$ & Non-FL & $\begin{array}{l}\mathrm{P} \\
\text { value }\end{array}$ \\
\hline Number(\%) & $\begin{array}{l}98 \\
(14.89)\end{array}$ & $\begin{array}{l}88 \\
(13.37)\end{array}$ & 472(71.73) & & $\begin{array}{l}86 \\
(87.76)\end{array}$ & $\begin{array}{l}75 \\
(85.23)\end{array}$ & $\begin{array}{l}269 \\
(56.99)\end{array}$ & & $\begin{array}{l}12 \\
(12.24)\end{array}$ & $\begin{array}{l}13 \\
(14.77)\end{array}$ & $\begin{array}{l}203 \\
(43.01)\end{array}$ & \\
\hline Age, years & $\begin{array}{l}45.20 \pm \\
11.35\end{array}$ & $\begin{array}{l}45.78 \pm \\
10.70\end{array}$ & $\begin{array}{l}43.42 \pm \\
11.50\end{array}$ & 0.11 & $\begin{array}{l}43.26 \\
\pm 10.25\end{array}$ & $\begin{array}{l}43.12 \\
\pm 10.66\end{array}$ & $\begin{array}{l}43.81 \\
\pm 11.36\end{array}$ & $\overrightarrow{0.01}$ & $\begin{array}{l}59.17 \\
\pm 8.96\end{array}$ & $\begin{array}{l}49.62 \\
\pm 10.52\end{array}$ & $\begin{array}{l}42.89 \\
\pm 11.69\end{array}$ & $\dot{0} 01$ \\
\hline \multicolumn{13}{|c|}{$\begin{array}{l}\text { Anthropometric } \\
\text { indices }\end{array}$} \\
\hline WC, cm & $\begin{array}{l}99.00 \pm \\
9.90\end{array}$ & $\begin{array}{l}93.93 \pm \\
8.76\end{array}$ & $83.69 \pm 7.81$ & $<.01$ & $\begin{array}{l}99.57 \\
\pm 9.58\end{array}$ & $\begin{array}{l}95.09 \\
\pm 8.44\end{array}$ & $\begin{array}{l}86.84 \\
\pm 6.88\end{array}$ & $\begin{array}{l}<.01 \\
0.01\end{array}$ & $\begin{array}{l}94.97 \\
\pm 11.55\end{array}$ & $\begin{array}{l}87.24 \\
\pm 7.26\end{array}$ & $\begin{array}{l}79.52 \\
\pm 6.97\end{array}$ & $\dot{0}_{0.01}$ \\
\hline WHR & $\begin{array}{l}0.96 \pm \\
0.06\end{array}$ & $\begin{array}{l}0.94 \pm \\
0.05\end{array}$ & $0.89 \pm 0.05$ & $\dot{0} 01$ & $\begin{array}{l}0.96 \pm \\
0.06\end{array}$ & $\begin{array}{l}0.95 \pm \\
0.05\end{array}$ & $\begin{array}{l}0.90 \pm \\
0.04\end{array}$ & $\begin{array}{l}<.01 \\
0.01\end{array}$ & $\begin{array}{l}0.97 \pm \\
0.05\end{array}$ & $\begin{array}{l}0.92 \pm \\
0.05\end{array}$ & $\begin{array}{l}0.88 \pm \\
0.05\end{array}$ & $\dot{0} 01$ \\
\hline BMI, kg/m² & $\begin{array}{l}27.94 \pm \\
3.40\end{array}$ & $\begin{array}{l}26.07 \pm \\
2.69\end{array}$ & $23.02 \pm 2.78$ & $\dot{0.01}$ & $\begin{array}{l}28.06 \\
\pm 3.22\end{array}$ & $\begin{array}{l}26.32 \\
\pm 2.63\end{array}$ & $\begin{array}{l}23.86 \\
\pm 2.56\end{array}$ & $\dot{0.01}$ & $\begin{array}{l}27.14 \\
\pm 4.64\end{array}$ & $\begin{array}{l}24.65 \\
\pm 2.73\end{array}$ & $\begin{array}{l}21.92 \\
\pm 2.68\end{array}$ & $\dot{0} 01$ \\
\hline BFM, kg & $\begin{array}{l}25.26 \pm \\
7.04\end{array}$ & $\begin{array}{l}21.76 \pm \\
5.49\end{array}$ & $17.05 \pm 4.61$ & $\dot{0} 01$ & $\begin{array}{l}25.21 \\
\pm 6.86\end{array}$ & $\begin{array}{l}21.76 \\
\pm 5.64\end{array}$ & $\begin{array}{l}17.03 \\
\pm 4.67\end{array}$ & $\dot{0.01}$ & $\begin{array}{l}25.64 \\
\pm 8.54\end{array}$ & $\begin{array}{l}21.75 \\
\pm 4.76\end{array}$ & $\begin{array}{l}17.06 \\
\pm 4.59\end{array}$ & $\begin{array}{l}<.01 \\
0.01\end{array}$ \\
\hline VFA, $\mathrm{cm}^{2}$ & $\begin{array}{l}115.68 \\
\pm 37.37\end{array}$ & $\begin{array}{l}97.90 \pm \\
29.24\end{array}$ & $\begin{array}{l}75.83 \pm \\
24.71\end{array}$ & $\begin{array}{l}<.01 \\
0.01\end{array}$ & $\begin{array}{l}113.42 \\
\pm 35.77\end{array}$ & $\begin{array}{l}96.24 \\
\pm 29.18\end{array}$ & $\begin{array}{l}73.10 \\
\pm 21.87\end{array}$ & $\begin{array}{l}<.01 \\
0.01\end{array}$ & $\begin{array}{l}131.88 \\
\pm 45.86\end{array}$ & $\begin{array}{l}107.48 \\
\pm 28.80\end{array}$ & $\begin{array}{l}79.45 \\
\pm 27.67\end{array}$ & $\begin{array}{l}<.01 \\
0.01\end{array}$ \\
\hline \multicolumn{13}{|l|}{$\begin{array}{l}\text { Metabolic } \\
\text { indices }\end{array}$} \\
\hline TG/HDL & $\begin{array}{l}5.17 \pm \\
1.47\end{array}$ & $\begin{array}{l}4.66 \pm \\
0.99\end{array}$ & $3.94 \pm 1.00$ & $\begin{array}{l}<.01 \\
0.01\end{array}$ & $\begin{array}{l}5.25 \pm \\
1.52\end{array}$ & $\begin{array}{l}4.72 \pm \\
0.89\end{array}$ & $\begin{array}{l}4.26 \pm \\
1.01\end{array}$ & $\begin{array}{l}<.01 \\
0.01\end{array}$ & $\begin{array}{l}4.54 \pm \\
0.76\end{array}$ & $\begin{array}{l}4.29 \pm \\
1.41\end{array}$ & $\begin{array}{l}3.50 \pm \\
0.80\end{array}$ & $\begin{array}{l}< \\
0.01\end{array}$ \\
\hline AST/ALT & $\begin{array}{l}0.79 \pm \\
0.27\end{array}$ & $\begin{array}{l}0.86 \pm \\
0.29\end{array}$ & $1.20 \pm 0.45$ & $\begin{array}{l}<.01 \\
0.01\end{array}$ & $\begin{array}{l}0.76 \pm \\
0.27\end{array}$ & $\begin{array}{l}0.85 \pm \\
0.30\end{array}$ & $\begin{array}{l}1.07 \pm \\
0.39\end{array}$ & $\begin{array}{l}<.01 \\
0.01\end{array}$ & $\begin{array}{l}0.97 \pm \\
0.22\end{array}$ & $\begin{array}{l}0.93 \pm \\
0.21\end{array}$ & $\begin{array}{l}1.39 \pm \\
0.45\end{array}$ & $\dot{0.01}$ \\
\hline SBP, mmHg & $\begin{array}{l}129.02 \\
\pm 17.13\end{array}$ & $\begin{array}{l}128.65 \\
\pm 15.65\end{array}$ & $\begin{array}{l}120.07 \pm \\
16.85\end{array}$ & $\begin{array}{l}<.01 \\
0.01\end{array}$ & $\begin{array}{l}128.67 \\
\pm 12.38\end{array}$ & $\begin{array}{l}128.47 \\
\pm 13.02\end{array}$ & $\begin{array}{l}123.04 \\
\pm 15.54\end{array}$ & $\begin{array}{l}<.01 \\
0.01\end{array}$ & $\begin{array}{l}131.50 \\
\pm 20.74\end{array}$ & $\begin{array}{l}129.69 \\
\pm 26.98\end{array}$ & $\begin{array}{l}116.13 \\
\pm 17.72\end{array}$ & $\begin{array}{l}< \\
0.01\end{array}$ \\
\hline DBP, mmHg & $\begin{array}{l}79.92 \pm \\
11.76\end{array}$ & $\begin{array}{l}79.95 \pm \\
11.33\end{array}$ & $\begin{array}{l}72.63 \pm \\
10.88\end{array}$ & $\begin{array}{l}<.01 \\
0.01\end{array}$ & $\begin{array}{l}80.12 \\
\pm 12.05\end{array}$ & $\begin{array}{l}80.83 \\
\pm 11.00\end{array}$ & $\begin{array}{l}75.68 \\
\pm 10.33\end{array}$ & $\begin{array}{l}< \\
0.01\end{array}$ & $\begin{array}{l}78.50 \\
\pm 9.73\end{array}$ & $\begin{array}{l}74.92 \\
\pm 12.39\end{array}$ & $\begin{array}{l}68.57 \\
\pm 10.27\end{array}$ & $\begin{array}{l}<.01 \\
0.01\end{array}$ \\
\hline FBG, mmol/l & $\begin{array}{l}98 \\
(14.89 \%)\end{array}$ & $\begin{array}{l}88 \\
(13.37 \%)\end{array}$ & $472(71.73 \%)$ & $\begin{array}{l}<.01 \\
0.01\end{array}$ & $\begin{array}{l}6.58 \pm \\
2.92\end{array}$ & $\begin{array}{l}5.57 \pm \\
1.13\end{array}$ & $\begin{array}{l}5.27 \pm \\
0.84\end{array}$ & $\begin{array}{l}<.01 \\
0.01\end{array}$ & $\begin{array}{l}5.80 \pm \\
0.85\end{array}$ & $\begin{array}{l}5.41 \pm \\
0.40\end{array}$ & $\begin{array}{l}5.09 \pm \\
0.56\end{array}$ & $\begin{array}{l}< \\
0.01\end{array}$ \\
\hline
\end{tabular}

Univariate analyses showed the significant associations between anthropometric indices, metabolic indices and FL. When including these indices into the multivariate ranked logistic regression analysis, AGE, WC, TG/HDL, AST/ALT and FBG showed a significant relationship with FL ( $\beta=0.03,0.19,0.41$, -1.89 and $0.28, O R=1.03,1.21,1.51,0.15$, and 1.32, $P<0.05$, Table 2). 
Table 2

OR and their $95 \% \mathrm{Cls}$ in Multivariate Analysis of FL

\begin{tabular}{|c|c|c|c|}
\hline Variables & Beta & $P$ & OR $(95 \% \mathrm{Cl})$ \\
\hline Gender & 0.57 & $>0.05$ & $1.77(0.74,4.18)$ \\
\hline Female & - & & \\
\hline \multicolumn{4}{|l|}{ Male } \\
\hline Age & 0.03 & 0.01 & $1.03(1.01,1.05)$ \\
\hline \multicolumn{4}{|c|}{ Anthropometric indices } \\
\hline WC, $\mathrm{cm}$ & 0.19 & 0.01 & $1.21(1.05,1.40)$ \\
\hline WHR & -9.61 & $>0.05$ & 0 \\
\hline BMI, kg/m² & 1.07 & $>0.05$ & $1.07(0.84,1.35)$ \\
\hline BFM, kg & -0.10 & $>0.05$ & $0.90(0.71,1.74)$ \\
\hline VFA, $\mathrm{cm}^{2}$ & 0.01 & $>0.05$ & $1.01(0.97,1.49)$ \\
\hline \multicolumn{4}{|c|}{ Metabolic indices } \\
\hline TG/HDL & 0.41 & $<0.01$ & $1.51(1.22,1.86)$ \\
\hline AST/ALT & -1.89 & $<0.01$ & $0.15(0.07,0.34)$ \\
\hline SBP, mmHg & 0 & $>0.05$ & $0(0.98,1.02)$ \\
\hline DBP, mmHg & 0.01 & $>0.05$ & $1.01(0.98,1.04)$ \\
\hline FBG, mmol/l & 0.28 & $<0.01$ & $1.32(1.12,1.57)$ \\
\hline
\end{tabular}

To assess the accuracy of anthropometric and metabolic indices for predicting FL (including FL and Mild-FL), AUC were conducted and showed in Table 3. Among all the indices, WC showed to be the best predictors with an AUC of 0.86 in participants. All indices showed AUCs over 0.6 except AST/ALT with an AUC of 0.22 .

Table 3

$\mathrm{ROC}$ of Anthropometric and Metabolic indices for FL

\begin{tabular}{|c|c|c|}
\hline Variables & $\operatorname{AUC}(95 \% \mathrm{Cl})$ & $P$ \\
\hline \multicolumn{3}{|c|}{ Anthropometric indices } \\
\hline WC, $\mathrm{cm}$ & $0.86(0.83,0.89)$ & $<0.01$ \\
\hline WHR & $0.81(0.77,0.84)$ & $<0.01$ \\
\hline BMI, $\mathrm{kg} / \mathrm{m}^{2}$ & $0.83(0.80,0.87)$ & $<0.01$ \\
\hline BFM, kg & $0.80(0.76,0.84)$ & $<0.01$ \\
\hline VFA, $\mathrm{cm}^{2}$ & $0.78(0.74,0.82)$ & $<0.01$ \\
\hline \multicolumn{3}{|c|}{ Metabolic indices } \\
\hline TG/HDL & $0.75(0.71,0.79)$ & $<0.01$ \\
\hline AST/ALT & $0.22(0.18,0.26)$ & $<0.01$ \\
\hline SBP, mmHg & $0.66(0.62,0.71)$ & $<0.01$ \\
\hline DBP, mmHg & $0.68(0.64,0.73)$ & $<0.01$ \\
\hline FBG, mmol// & $0.68(0.63,0.73)$ & $<0.01$ \\
\hline
\end{tabular}

\section{Discussion}


In this cross-sectional survey, we explored the comprehensive relationship between anthropometric indices, metabolic indices and FL and found that these indices have regulation and prediction effect on FL with a very complex pattern. To be specific, we demonstrated that 1) AST/ALT had strongest negative association with FL prevalence, while had the lowest predictive value for FL; and that 2) WC possessed the highest ability on predicting FL among all these indices.

The association of obesity with FL has been established in multiple previous studies[11, 15, 27, 28]. Epidemiological studies propose a causative link between obesity and progressive liver disease in individuals[15,28]. Obesity has been linked not only to initial stages of the disease, but also to its severity[11]. The pathophysiology and clinical studies have shown that the progression of FL results from an imbalance between lipid uptake and lipid disposal and eventually causes oxidative stress and hepatocyte injury[29]. Obesity can be expressed in clinical practice by several methods, including anthropometric and metabolic ways[24]. Some studies thought that the visceral adiposity was the main adipose depot responsible for FL and was associated with FL in a dose-dependent manner in a cohort study[30]. WC, WHR and BMI have been proved and used in many clinical trials as an indicator of the severity of fatty liver disease[19, 22]. BFM and VFA are often reported markers in athletes related articles or are used to explore the relationship between insulin resistance and excessive visceral fat accumulation[31, 32]. Additionally, elevated data strongly suggests that advanced blood lipids, blood pressure and blood sugar could also be lead to more severe histological changes and poorer clinical outcomes[14, 22, 33]. Once FL is established, insulin resistance can promote the progression to the more severe state of liver endangerment like non-alcoholic steatohepatitis. Although the relationship between these ten obesity related indexes (WC, WHR, BMI, BFM, VFA, TG/HDL, AST/ALT, SBP, DBP and FBG) and FL were analyzed separately in many articles, few articles put them together to evaluate. Our studies compared all these 10 obesity related indexes with FL and also stratified the data by gender, thus we are capable of determining which factors might be critical for the regulation and prediction of FL.

In our study, we found differences of these ten obesity related indexes in three groups after stratifying the data. Men had a similar prevalence of FL regardless of age, whereas in women the prevalence of FL increased steadily with age. As we all know that sex hormones play a central role in predisposing individuals to metabolic status. Loss of estrogen after menopause leads to extensive changes in the metabolic system, including an increase in visceral adiposity. Although FL is primarily a male disease, the alteration in sex hormone levels, specifically reduced estrogens and increased androgens during and after menopause, is an important factor in the emergence of FL for female subjects[34, 35].

In our studies, we found blood lipids, blood sugar, WC and liver inflammatory indicators showed significant correlation with FL, while AST/ALT had a strongest negative association with increased FL prevalence. As we know, liver inflammation is closely related to metabolic disorders because the liver plays a central role in metabolism of lipids and glucose[7]. Obesity and inflammation exist in the same time in FL almost, successive stages in FL may be reflected by the accumulation of fat in hepatocytes and the onset of steatohepatitis. Although the etiology of FL is multifactorial, it is well accepted that inflammation is a central component of FL pathogenesis[36, 37]. This may explain why the AST/ALT has the maximum increase in our study. And it is also agree with current treatment measures on FL[7]. Besides, we found WC have a strong association with FL compared with VFA. This is in consistent with the study by Church et al. who found that adjustment for VFA attenuated the direct association between waist circumference and $\mathrm{FL}[38]$.

We further identified AST/ALT had the lowest predictive value for FL, while WC showed a correspondingly higher ability on prediction in all these indices. Nowadays, the mechanisms of hepatic steatosis and steatohepatitis are being investigated extensively which are regulated by complex pathways[36, 39]. Although inflammation contribute greatly to $\mathrm{FL}$, abdominal obesity remains the main manifestations for $\mathrm{FL}$. Compared with inflammatory changes existed in many diseases, WC have been shown in many studies to be directly related to fatty liver and to be more specific for $\mathrm{FL}[40-42]$.

This study characterized and analyzed a comprehensive profile for FL related indices, especially different anthropometric and metabolic indices. These comprehensive correlation analyses can enhance our understanding of the mechanisms for hepatic steatosis and steatohepatitis and is also important for developing strategies for the prevention and treatment of FL. However, there are still some limitations. Firstly, our findings are based on a crosssectional study, a large-scale cohort study is still necessary to build the definite causal relationship between these indices and FL. Secondly, the data of other confounders, such as, smoking and drinking status and exercise, were not included in this analysis because of the information default.

In summary, this is a comprehensive profile for FL related indices. We identified AST/ALT had a strongest negative association with increased FL prevalence, but had the lowest predictive value for FL. Meantime, WC showed a correspondingly higher ability on predicting FL in all these indices. Findings from our study could provide further theoretical evidence for the understanding of relevant mechanisms for hepatic steatosis and steatohepatitis, as well as for predicting the prevalence of FL.

\section{Abbreviations}

FL

Fatty Liver

BMI

Body Mass Index

BFM

Body Fat Mass

VFA 
Visceral Fat Area

TC

Triglyceride

TG

Triglyceride

HDL

High Density lipoprotein

FBG

Fasting Blood Glucose

$\mathrm{OR}$

Odds Ratio

$\mathrm{Cl}$

Confidence Interval

AUC

Area Under the Curve

ROC

Receiver Operating Characteristic

\section{Declarations}

\section{Statement of Ethics}

The study was approved by the ethical committee of the Affiliated Suzhou Hospital of Nanjing Medical University. Subjects agreeing to participate into the present study provided a written informed consent.

\section{Conflict of Interest Statement}

The authors declare that there is no competing interests.

\section{Funding Sources}

No funding.

\section{Author Contributions}

XFF PYY and SKY designed the study, analyzed the data and wrote the manuscript. WY, LJY, XXH, ZH collected the data. All authors read and approved the final manuscript.

\section{References}

1. Liu K, McCaughan GW. Epidemiology and Etiologic Associations of Non-alcoholic Fatty Liver Disease and Associated HCC. Advances in experimental medicine and biology. 2018; 1061:3-18.

2. Leoni S, Tovoli F, Napoli L, Serio I, Ferri S, Bolondi L. Current guidelines for the management of non-alcoholic fatty liver disease: A systematic review with comparative analysis. World journal of gastroenterology. 2018;24(30):3361-73.

3. Araujo AR, Rosso N, Bedogni G, Tiribelli C, Bellentani S. Global epidemiology of non-alcoholic fatty liver disease/non-alcoholic steatohepatitis: What we need in the future. Liver international: official journal of the International Association for the Study of the Liver. 2018;38(Suppl 1):47-51.

4. Andronescu Cl, Purcarea MR, Babes PA. Nonalcoholic fatty liver disease: epidemiology, pathogenesis and therapeutic implications. Journal of medicine life. 2018;11(1):20-3.

5. Perumpail BJ, Khan MA, Yoo ER, Cholankeril G, Kim D, Ahmed A. Clinical epidemiology and disease burden of nonalcoholic fatty liver disease. World journal of gastroenterology. 2017;23(47):8263-76.

6. Sanyal AJ. Past, present and future perspectives in nonalcoholic fatty liver disease. Nature Reviews Gastroenterology Hepatology. 2019;16(6):37786.

7. Marchisello S, Di Pino A, Scicali R, Urbano F, Piro S, Purrello F, et al. Pathophysiological, Molecular and Therapeutic Issues of Nonalcoholic Fatty Liver Disease: An Overview. International journal of molecular sciences. 2019; 20(8).

8. Wijarnpreecha K, Panjawatanan P, Aby E, Ahmed A, Kim D. Nonalcoholic fatty liver disease in the over-60s: Impact of sarcopenia and obesity. Maturitas. 2019;124:48-54.

9. Agbim U, Carr RM, Pickett-Blakely O, Dagogo-Jack S. Ethnic Disparities in Adiposity: Focus on Non-alcoholic Fatty Liver Disease, Visceral, and Generalized Obesity. Current obesity reports. 2019;8(3):243-54. 
10. Mantovani A, Byrne CD, Bonora E, Targher G. Nonalcoholic Fatty Liver Disease and Risk of Incident Type 2 Diabetes: A Meta-analysis. Diabetes Care. 2018;41(2):372-82.

11. Polyzos SA, Kountouras J, Mantzoros CS. Adipose tissue, obesity and non-alcoholic fatty liver disease. Minerva Endocrinol. 2017;42(2):92-108.

12. Chao HW, Chao SW, Lin H, Ku HC, Cheng CF. Homeostasis of Glucose and Lipid in Non-Alcoholic Fatty Liver Disease. International journal of molecular sciences. 2019; 20(2).

13. Targher G, Li Y, Wang J, Tang Y, Han X, Liu B, et al. Bidirectional association between nonalcoholic fatty liver disease and type 2 diabetes in Chinese population: Evidence from the Dongfeng-Tongji cohort study. PloS one. 2017;12(3):e0174291.

14. Arrese M, Barrera F, Triantafilo N, Arab JP. Concurrent nonalcoholic fatty liver disease and type 2 diabetes: diagnostic and therapeutic considerations. Expert Review of Gastroenterology Hepatology. 2019;13(9):849-66.

15. Li L, Liu DW, Yan HY, Wang ZY, Zhao SH, Wang B. Obesity is an independent risk factor for non-alcoholic fatty liver disease: evidence from a metaanalysis of 21 cohort studies. Obesity Reviews An Official Journal of the International Association for the Study of Obesity. 2016;17(6):510.

16. Lee MJ, Kim EH, Bae SJ, Kim GA, Park SW, Choe J, et al. Age-Related Decrease in Skeletal Muscle Mass Is an Independent Risk Factor for Incident Nonalcoholic Fatty Liver Disease: A 10-Year Retrospective Cohort Study. Gut Liver. 2019;13(1):67-76.

17. Xie F, Zhou H, Wang Y. Atherogenic index of plasma is a novel and strong predictor associated with fatty liver: a cross-sectional study in the Chinese Han population. Lipids Health Dis. 2019;18(1):170.

18. Wang Q, Zheng D, Liu J, Fang L, Li Q. Atherogenic index of plasma is a novel predictor of non-alcoholic fatty liver disease in obese participants: a cross-sectional study. Lipids Health Dis. 2018;17(1):284.

19. VanWagner LB, Khan SS, Ning H, Siddique J, Lewis CE, Carr JJ, et al. Body mass index trajectories in young adulthood predict non-alcoholic fatty liver disease in middle age: The CARDIA cohort study. Liver international: official journal of the International Association for the Study of the Liver. 2018;38(4):706-14.

20. Chen Z, Qin H, Qiu S, Chen G, Chen Y. Correlation of triglyceride to high-density lipoprotein cholesterol ratio with nonalcoholic fatty liver disease among the non-obese Chinese population with normal blood lipid levels: a retrospective cohort research. Lipids in health and disease. 2019; 18(1).

21. Rachakonda V, Wills R, DeLany JP, Kershaw EE, Behari J. Differential Impact of Weight Loss on Nonalcoholic Fatty Liver Resolution in a North American Cohort with Obesity. Obesity. 2017;25(8):1360-8.

22. Ren XY, Shi D, Ding J, Cheng ZY, Li HY, Li JS, et al. Total cholesterol to high-density lipoprotein cholesterol ratio is a significant predictor of nonalcoholic fatty liver: Jinchang cohort study. Lipids Health Dis. 2019;18(1):47.

23. An T, Song Y, Yang Y, Guo M, Liu H, Liu K, et al. Non-HDL-cholesterol to HDL-cholesterol ratio is an independent risk factor for liver function tests abnormalities in geriatric population. Lipids Health Dis. 2018;17(1):296.

24. McLester CN, Nickerson BS, Kliszczewicz BM, McLester JR. Reliability and Agreement of Various InBody Body Composition Analyzers as Compared to Dual-Energy X-Ray Absorptiometry in Healthy Men and Women. Journal of clinical densitometry: the official journal of the International Society for Clinical Densitometry. 2018.

25. Arienti V, Aluigi L, Pretolani S, Accogli E, Polimeni L, Domanico A, et al. Ultrasonography (US) and non-invasive diagnostic methods for nonalcoholic fatty liver disease (NAFLD) and early vascular damage. Possible application in a population study on the metabolic syndrome (MS). Internal and emergency medicine. 2012; 7Suppl 3:S283-290.

26. Khanal UP, Paudel B, Gurung G, Hu YS, Kuo CW. Correlational Study of Nonalcoholic Fatty Liver Disease Diagnosed by Ultrasonography with Lipid Profile and Body Mass Index in Adult Nepalese Population. Journal of medical ultrasound. 2019;27(1):19-25.

27. Bedossa P. Pathology of non-alcoholic fatty liver disease. Liver international: official journal of the International Association for the Study of the Liver. 2017;37(Suppl 1):85-9.

28. Mahli A, Hellerbrand C. Alcohol and Obesity: A Dangerous Association for Fatty Liver Disease. Digestive diseases. 2016;34(Suppl 1):32-9.

29. Cholankeril G, Wong RJ, Hu M, Perumpail RB, Yoo ER, Puri P, et al. Liver Transplantation for Nonalcoholic Steatohepatitis in the US: Temporal Trends and Outcomes. Dig Dis Sci. 2017;62(10):2915-22.

30. Kim D, Chung GE, Kwak MS, Seo HB, Kang JH, Kim W, et al. Body Fat Distribution and Risk of Incident and Regressed Nonalcoholic Fatty Liver Disease. Clinical gastroenterology hepatology: the official clinical practice journal of the American Gastroenterological Association. 2016;14(1):132-8 e134.

31. Umano GR, Shabanova V, Pierpont B, Mata M, Nouws J, Trico D, et al. A low visceral fat proportion, independent of total body fat mass, protects obese adolescent girls against fatty liver and glucose dysregulation: a longitudinal study. Int J Obes. 2019;43(4):673-82.

32. Nirengi S, Fujibayashi M, Furuno S, Uchibe A, Kawase Y, Sukino S, et al. Nonalcoholic Fatty Liver Disease in University Rugby Football Players. Front Endocrinol. 2018;9:341.

33. Oikonomou D, Georgiopoulos G, Katsi V, Kourek C, Tsioufis C, Alexopoulou A, et al. Non-alcoholic fatty liver disease and hypertension: coprevalent or correlated? Eur J Gastroenterol Hepatol. 2018;30(9):979-85.

34. Hörist-Kollmann S, Strametz-Juranek J. Female Dietary Patterns and the Pathogenesis of NAFLD. Gender the Genome. 2018;2(2):49-55.

35. Cai M-J, Kong X-N, Zhao X-Y. Influences of Gender and Age on the Prevalence and Complications of Nonalcoholic Fatty Liver Disease. Acta Academiae Medicinae Sinicae. 2017;39(4):499-505.

Page $7 / 8$ 
36. Koyama Y, Brenner DA. Liver inflammation and fibrosis. Journal of Clinical Investigation. 2017;127(1):55-64.

37. Chedid MF. Nonalcoholic Steatohepatitis: The Second Leading Indication for Liver Transplantation in the USA. Dig Dis Sci. 2017;62(10):2621-2.

38. Eguchi Y, Eguchi T, Mizuta T, Ide Y, Yasutake T, Iwakiri R, et al. Visceral fat accumulation and insulin resistance are important factors in nonalcoholic fatty liver disease. Journal of gastroenterology. 2006;41(5):462-9.

39. Clugston RD, Gao MA, Blaner WS. The Hepatic Lipidome: A Gateway to Understanding the Pathogenes is of Alcohol-Induced Fatty Liver. Current Molecular Pharmacology. 2017;10(3):195-206.

40. Tantanavipas S, Vallibhakara O, Sobhonslidsuk A, Phongkitkarun S, Vallibhakara SA, Promson K, et al. Abdominal Obesity as a Predictive Factor of Nonalcoholic Fatty Liver Disease Assessed by Ultrasonography and Transient Elastography in Polycystic Ovary Syndrome and Healthy Women. BioMed research international. 2019; 2019:9047324.

41. Park SK, Ryoo JH, Choi JM, Seo MW, Park CM. The Risk of Abdominal Obesity according to the Degree of Non-Alcoholic Fatty Liver Disease in Korean Men. J Korean Med Sci. 2016;31(3):410-6.

42. Jakobsen MU, Berentzen T, Sorensen TI, Overvad K. Abdominal obesity and fatty liver. Epidemiol Rev. 2007;29:77-87. 